\title{
Down-regulation of miR-221 and miR-222 correlates with pronounced Kit expression in gastrointestinal stromal tumors
}

\author{
MARITA KOELZ ${ }^{1 *}$, JOSEFINE LENSE ${ }^{2 *}$, FRITZ WRBA $^{1}$, MELANIE SCHEFFLER $^{2}$, \\ HANS PETER DIENES ${ }^{2}$ and MARGARETE ODENTHAL ${ }^{2}$ \\ ${ }^{1}$ Clinical Institute of Pathology, Medical University of Vienna, Austria; \\ ${ }^{2}$ Institute of Pathology, University Hospital of Cologne, Cologne, Germany
}

Received September 9, 2010; Accepted October 29, 2010

DOI: $10.3892 /$ ijo.2010.857

\begin{abstract}
Gastrointestinal stromal tumors (GISTs), are characterized by mutations of the KIT or platelet-derived growth factor receptor- $\alpha$ gene and the constitutive expression of Kit, which is currently being studied as a potential therapeutic target. In this study, we addressed the question of whether the microRNA (miRNA) 221/222 cluster (miR-221/ 222 ), which has been shown to be dysregulated in many malignancies, is linked to GIST diagnosis and prognosis, and whether it could provide a basis for possible therapeutic approaches. We analyzed the expression of miR-221 and miR-222 in 54 formalin-fixed and paraffin-embedded GISTs and corresponding peripheral non-tumorous tissue by realtime PCR. The miRNA-expression levels were studied in relation to histomorphological parameters, KIT mutation status and immunohistochemical Kit expression. miR-221 and miR-222, were reduced in most of the GISTs, in contrast to other tumors. No correlation was observed between miR-221/ 222 expression levels and histomorphological parameters, tumor risk grade, or KIT mutation status. However, we found major differences in miRNA expression among the different groups of immunohistochemical Kit expression, especially between Kit-negative and -positive tumors. The expression levels of miR-221 and miR-222 were significantly repressed in Kit-positive GISTs, compared to normal tissue, whereas Kit-negative GISTs exhibited a completely inverse expression pattern. This study shows for the first time that miR-221 and
\end{abstract}

Correspondence to: Dr Marita Koelz, Clinical Institute of Pathology, Medical University of Vienna, Währinger Gürtel 18-20, A-1090 Vienna, Austria

E-mail: marita.koelz@meduniwien.ac.at

Dr Margarete Odenthal, Institute of Pathology, University Hospital of Cologne, Kerpener Strasse 62, D-50924 Cologne, Germany E-mail:m.odenthal@uni-koeln.de

${ }^{*}$ Contributed equally

Key words: gastrointestinal stromal tumors, microRNA 221, microRNA 222, Kit expression, new therapeutic tool
miR-222 can act as regulators of Kit expression in GISTs and hence reveals a new aspect in the molecular pathogenesis of these tumors. Although miR-221/222 expression does not have an impact on diagnostics, it could be considered as a tool for future therapeutic strategies for GISTs, especially for tumors with secondary resistance to tyrosine kinase inhibitors.

\section{Introduction}

Gastrointestinal stromal tumors (GISTs) are the most common mesenchymal tumors of the digestive tract. The interstitial cells of Cajal (ICCs), the so-called gastrointestinal pacemaker cells, are believed to form the histogenetic matrix of these tumors. GISTs show a typical histomorphology with either a spindle, epithelioid, or mixed cell type. The characteristic immunohistochemical feature is the frequent expression of Kit and CD34 in most of the tumors (1-3).

The central event in the pathogenesis of these tumors is gain-of-function mutations of type III receptor tyrosine kinases, in particular Kit or the related platelet-derived growth factor receptor- $\alpha$ (PDGFRA) $(4,5)$. The vast majority of GISTs harbour primary KIT gene mutations in exons 9 or 11, but the frequencies reported by many studies so far, vary between 42 and $>90 \%$ (6-8). GISTs have served as a prototype of tumors for molecular diagnostics and also as a model of solid tumors for molecular targeted therapy, as these tumors are resistant to conventional radiotherapy and chemotherapeutics. The current therapy for these tumors is based on surgery and receptor tyrosine kinase inhibitors, such as imatinib and sunitinib $(9,10)$. Response to therapy with tyrosine kinase inhibitors depends on the mutation status of these tumors $(11,12)$. Furthermore, half of the patients develop secondary resistance, due to secondary mutations affecting the tyrosine kinase domains of the receptor $(13,14)$.

In addition to mutations in the KIT gene, a strong Kit expression in $>95 \%$ of the tumors is another main molecular feature $(1,2)$. However, the molecular mechanisms of the Kit expression in GISTs are not yet well understood. The Kit overexpression is rarely related to gene amplification, but transcriptional and post-transcriptional dysregulation have lately been considered (15). Studies have shown that genetic dysregulation during carcinogenesis is often due to an altered microRNA (miRNA) pattern (16-18). 
miRNAs are small non-coding RNAs that influence gene expression post-transcriptionally and hence control approximately one third of all protein-encoding genes $(19,20)$. They play fundamental roles in diverse cellular processes, such as development, differentiation, proliferation and apoptosis $(21,22)$. Therefore, the dysregulation of miRNA expression has been suggested to be one of the most important features contributing to carcinogenesis (23-25). Over the past years, numerous miRNAs have been discovered and their impact on carcinogenesis has been described in detail. So far, certain miRNAs have been classified as oncogenic and others as tumor suppressor miRNAs $(24,26,27)$. For example, miR-15 and miR-16 were the first defined miRNAs with tumor suppressive functions in B-cell chronic lymphocytic leukaemia, by suppressing BCL2 $(24,28)$. Other examples of tumor suppressor miRNAs include let-7, which regulates Ras and other cell cycle involved genes in lung cancer (29), or miR-143 and miR-145 in colon cancer $(30,31)$. The first reported oncogenic miRNAs were from the miR-17-92 cluster, which is amplified in human B-cell lymphomas and miR-155, which is up-regulated in Burkitt's lymphoma (32-34).

miRNAs miR-221 and miR-222, have been described to be variably regulated during erythropoiesis and melanoma progression $(35,36)$. The miR-221/222 cluster has also been shown to be up-regulated in various malignancies, such as glioblastoma, papillary thyroid carcinoma, hepatocellular carcinoma, pancreatic cancer and prostate carcinoma (37-43).

In this study, we analyzed the expression of miR-221 and miR-222 in GISTs and demonstrate that both are significantly down-regulated in GISTs in comparison to the corresponding peripheral, non-tumorous tissue. Although no association was proven between miR-221 and miR-222 and tumor risk grade, proliferation rate or mutation status, the pronounced repression of miR-221 and miR-222 was limited to Kitpositive GISTs. Therefore, our data reveal miR-221 and miR-222 as putative new therapeutic agents for silencing Kit in GISTs.

\section{Material and methods}

Tissue samples. All specimens were obtained from the tumor bank of the Institute of Pathology at the University Hospital of Cologne, Germany, or from the Clinical Institute of Pathology of the Medical University of Vienna, Austria, and were used in accordance with the policies of the institutional review board of the hospital. All samples were fixed in $4.5 \%$ formalin in phosphate-buffered saline ( $\mathrm{pH} 7.5)$ and embedded in paraffin.

The first set of tumors was composed of three hepatocellular and papillary thyroid carcinomas, and gastrointestinal stromal tumors, respectively and the corresponding peripheral, non-tumorous tissue. This tumor set and the corresponding non-tumorous tissues were applied to molecular miRNA analyses.

The comprehensive study of miR-221 and miR-222 was performed on a well characterized cohort of 54 GISTs and their corresponding peripheral non-tumorous tissues taken from the resection margins of the surgical specimens. Hematoxylin and eosin (H\&E)-stained tissue sections of the tumorous and corresponding non-tumorous tissue were examined to ensure that the samples included either tumor or non-tumorous tissue only, otherwise the respective areas were macrodissected from three $5-\mu \mathrm{m}$ sections in the corresponding H\&E sections.

Characterisation of tumor samples. H\&E-stained tissue sections from the paraffin-embedded tumor tissue blocks were independently analyzed by two pathologists (M.K. and H.P.D.). The following histomorphological features of the tumors were evaluated: Cell type (spindle, epitheloid, or mixed cell type) and mitotic rate per 50 high-power fields. Furthermore, data concerning the localization and size of the tumors were collected. The risk grade was assessed according to the method described by Fletcher et al (2).

Immunohistochemical examination. The tumors were immunohistochemically analyzed for the expression of Kit (CD117), CD34, smooth muscle actin (SMA), S-100, desmin, vimentin and $\mathrm{Ki}-67$. Immunohistochemistry was performed as previously described $(44,45)$ using the ABC method based on the epitope labeling by the avidin-biotin peroxidase complex. Diaminobenzidine was used as the chromogen for immunostaining development. The antibodies, their sources, dilutions and pre-treatment, are summarized in Table I.

The expression of CD34, SMA, S-100, desmin and vimentin was evaluated as either positive or negative. The analysis of Kit expression was based on the proportion of cells that express Kit and staining intensity according to the following criteria: An extent score of $0(0 \%), 1(<25 \%), 2$ ( 25 to $<75 \%), 3(>75 \%)$ and an intensity score of 0 (no staining), 1 (weak staining), 2 (moderate staining) and 3 (strong staining). Cases with a 0 score in both instances, were regarded as negative, the cases with scores of 1 and 2 were assigned as weakly positive, cases with scores of 3 and 4 as moderately positive and the cases with scores of 5 and 6 as strongly positive. The Ki-67 score was given as the percentage of positively stained nuclei per counting of at least 1000 cells.

Analyses of the mutation status of the GISTs by sequencing exons 9 and 11 of the KIT gene and exons 12 and 18 of the PDGFRA gene. All GISTs were analyzed for KIT exon 9 and 11 mutations, as well as for mutations in exons 18 and 12 of the PDGFRA gene by polymerase chain reaction (PCR) amplification and genomic sequencing. DNA from the tumor tissues was prepared using the Purgene Tissue Core Kit A (Qiagen, Hilden, Germany) according to the manufacturer's instructions. The DNA yield was between 10 and $30 \mathrm{ng} / \mu 1$, which was determined by A260-measurement using a NanoDrop spectrophotometer (PeqLab Biotechnologie, Erlangen Germany). DNA extract $(2.5 \mu 1)$ was applied to the PCR analysis. Total volume $(25 \mu 1)$ of PCR reaction mix included $12.5 \mu 1$ RedTaq Ready Mix (Sigma, Dreisenhof, Germany), and 5 pmol of the reverse and forward primers, listed Table II. PCR was performed in a thermal cycler (Biometra Trio Thermoblock, Biometra, Goettingen, Germany), starting with a pre-incubation at $94^{\circ} \mathrm{C}$ for $5 \mathrm{~min}$, then followed by 35 cycles of $30-\mathrm{sec}$ dentaturation at $94^{\circ} \mathrm{C}$, 30 -sec annealing at $60^{\circ} \mathrm{C}$, and $30-\mathrm{sec}$ extension at $72^{\circ} \mathrm{C}$. For the nested PCR, $1 \mu 1$ DNA-template from the first PCR was 
Table I. Antibodies, their dilutions and pre-treatment.

\begin{tabular}{lccc}
\hline Antigen & Clone & Dilution & Pre-treatment \\
\hline CD117 & Polyclonal A4502 & $1 / 400$ & HIER, 25 min, citrate buffer, pH 6.0 \\
CD34 & Monoclonal QBEnd/10 & $1 / 400$ & HIER, 25 min, citrate buffer, pH 6.0 \\
SMA & Monoclonal 1A4 & $1 / 400$ & None \\
Desmin & Monoclonal D33 & $1 / 1000$ & None \\
Vimentin & Monoclonal V9 & $1 / 800$ & HIER, 25 min, citrate buffer, pH 6.0 \\
S100 & Polyclonal Z0311 & $1 / 1200$ & HIER, 15 min, trypsin buffer, pH 6.0 \\
Ki-67 & Monoclonal SP6 & $1 / 500$ & HIER, 25 min, citrate buffer, pH 6.0 \\
\hline
\end{tabular}

Antibody sources: Ki-67 from DCS, Hamburg, Germany, the other primary antibodies from Dako, Hamburg, Germany. HIER, heat-induced epitope retrieval.

Table II. Primers for PCR amplification.

\begin{tabular}{|c|c|c|c|}
\hline Gene/exon & $\mathrm{F} / \mathrm{R}$ & Primer in PCR 1 & Primer in PCR 2 \\
\hline \multirow[t]{4}{*}{ KIT exon 9} & $\mathrm{~F}$ & $\begin{array}{l}\text { 5'-TAA GCC AGG GCT TTT GTT } \\
\text { TTC-3' }\end{array}$ & $\begin{array}{l}\text { 5'-TGT AAA ACG ACG GCC AGT TCT TCC } \\
\text { CTT TAG ATG CTC TG-3' }\end{array}$ \\
\hline & $\mathrm{R}$ & $\begin{array}{l}\text { 5'-AAC ATC CCC TTA AAT TGG } \\
\text { ATT AAA-3' }\end{array}$ & $\begin{array}{l}\text { 5'-CAG GAA ACA GCT ATG ACC AGA AAT } \\
\text { ATA CCT TTG TTG TTA CCT-3' }\end{array}$ \\
\hline & $\mathrm{F}$ & $\begin{array}{l}\text { 5'-CTG TAC TGC CAG TGG ATG } \\
\text { TGC A-3' }\end{array}$ & 5'-TGT GCA GAC ACT AAA CTC ATC TGG-3' \\
\hline & $\mathrm{R}$ & $\begin{array}{l}\text { 5'-TAC ATT CAA CCG TGC CAT } \\
\text { TGT G-3' }\end{array}$ & 5'- GCC ATT GTG CTT GAA TGC AC-3' \\
\hline \multirow[t]{2}{*}{ KIT exon 11} & $\mathrm{~F}$ & $\begin{array}{l}\text { 5'-CAG AGT GCT CTA ATG ACT } \\
\text { GAG ACA A-3' }\end{array}$ & $\begin{array}{l}\text { 5'-CAG AGT GCT CTA ATG ACT GAG } \\
\text { ACA A-3' }\end{array}$ \\
\hline & $\mathrm{R}$ & $\begin{array}{l}\text { 5'-CAA AAA GGT GAC ATG GAA } \\
\text { AGC C-3' }\end{array}$ & 5'-CAT ACT GAC CAA AAC TCA GCC TG-3' \\
\hline \multirow[t]{2}{*}{ PDGFRA exon 12} & $\mathrm{~F}$ & $\begin{array}{l}\text { 5'-ACT TTG GTA ATT CAC CAG } \\
\text { TTA CCT G-3' }\end{array}$ & $\begin{array}{l}\text { 5'-TGT AAA ACG ACG GCC AGT CCA GTT } \\
\text { ACC TGT CCT GGT CAT T-3' }\end{array}$ \\
\hline & $\mathrm{R}$ & $\begin{array}{l}\text { 5'-GCA AGG GAA AAG GGA GTC } \\
\text { TTG-3' }\end{array}$ & $\begin{array}{l}\text { 5'-CAG GAA ACA GCT ATG ACC GAG } \\
\text { GTT ACC CCA TGG AAC TTA C-3' }\end{array}$ \\
\hline \multirow[t]{2}{*}{ PDGFRA exon 18} & $\mathrm{~F}$ & $\begin{array}{l}\text { 5'-ACA GAT GGC TTG ATC CTG } \\
\text { AGT C-3' }\end{array}$ & $\begin{array}{l}\text { 5'-TGT AAA ACG ACG GCC AGT TCC } \\
\text { TTT TCC ATG CAG TGT GTC-3' }\end{array}$ \\
\hline & $\mathrm{R}$ & $\begin{array}{l}\text { 5'-CCT GTC CAG TGT GGG AAG } \\
\text { TGT -3' }\end{array}$ & $\begin{array}{l}\text { 5'-CAG GAA ACA GCT ATG ACC GGA } \\
\text { AGT GTG GAC GTA GAC TGC-3' }\end{array}$ \\
\hline
\end{tabular}

F, forward; R, reverse.

applied for the second PCR. However, the annealing temperature for amplification of PDGFRA exon 18 in the second PCR was raised to $65^{\circ} \mathrm{C}$. PCR products were sequenced by Agowa (Berlin, Germany) by order.

miR-221 and miR-222 analyses. RNA isolation from formalinfixed paraffin-embedded tissue samples was performed as described previously (46). Extracts of total RNA were measured with the ND-1000 NanoDrop spectrophotometer (NanoDrop, Wilmington, DE), and $1 \mu \mathrm{g}$ of total RNA was reverse-transcribed in a $20-\mu 1$ reaction mix using the miScript Reverse Transcription Kit (Qiagen) according to the manu- facturer's recommendations. Then $5 \mathrm{ng}$ of cDNA were used in each of the real-time PCR assays with the miScript SYBRGreen PCR Kit (No. 218075; Qiagen) on a Stratagene MxPro 2000 thermocycler (Stratagene Europe, Amsterdam, The Netherlands) according to the manufacturer's instructions. Analyses of miR-221 and miR-222 were carried out in triplicate, after a standard curve of every assay in each run was generated to ascertain the specific amplification efficiency.

Data normalization and statistical evaluation. miR-221/222 expression data in tumor and corresponding peripheral nontumorous tissue samples were normalized to RNU6B levels. 
Table III. miR-221 and miR-222 expression levels in the set of preliminary analysed tumors.

\begin{tabular}{|c|c|c|c|c|c|c|}
\hline \multirow[t]{2}{*}{ Tissue } & \multicolumn{3}{|c|}{ miR-221 } & \multicolumn{3}{|c|}{$\operatorname{miR}-222$} \\
\hline & Case 1 & Case 2 & Case 3 & Case 1 & Case 2 & Case 3 \\
\hline Papillary thyroid carcinoma & 4.00 & 547.90 & 4377.10 & 2.60 & 306.14 & 147.73 \\
\hline Corresponding normal tissue & 45.38 & 0.09 & 0.06 & 40.24 & 0.33 & 0.33 \\
\hline Hepatocellular carcinoma & 64.91 & 80.18 & 47.12 & 8.70 & 27.21 & 14.19 \\
\hline Corresponding normal tissue & 8.79 & 19.01 & 8.87 & 9.42 & 7.79 & 6.52 \\
\hline Gastrointestinal stromal tumors & 6.17 & 1.65 & 18.38 & 20.27 & 9.21 & 6.95 \\
\hline Corresponding normal tissue & 7.96 & 50.42 & 42.69 & 25.03 & 18.13 & 73.63 \\
\hline
\end{tabular}

The mean miR-levels, calculated from triplicate experiments and normalized to the RNU6B levels of the preliminary analyzed set of tumors, are shown.
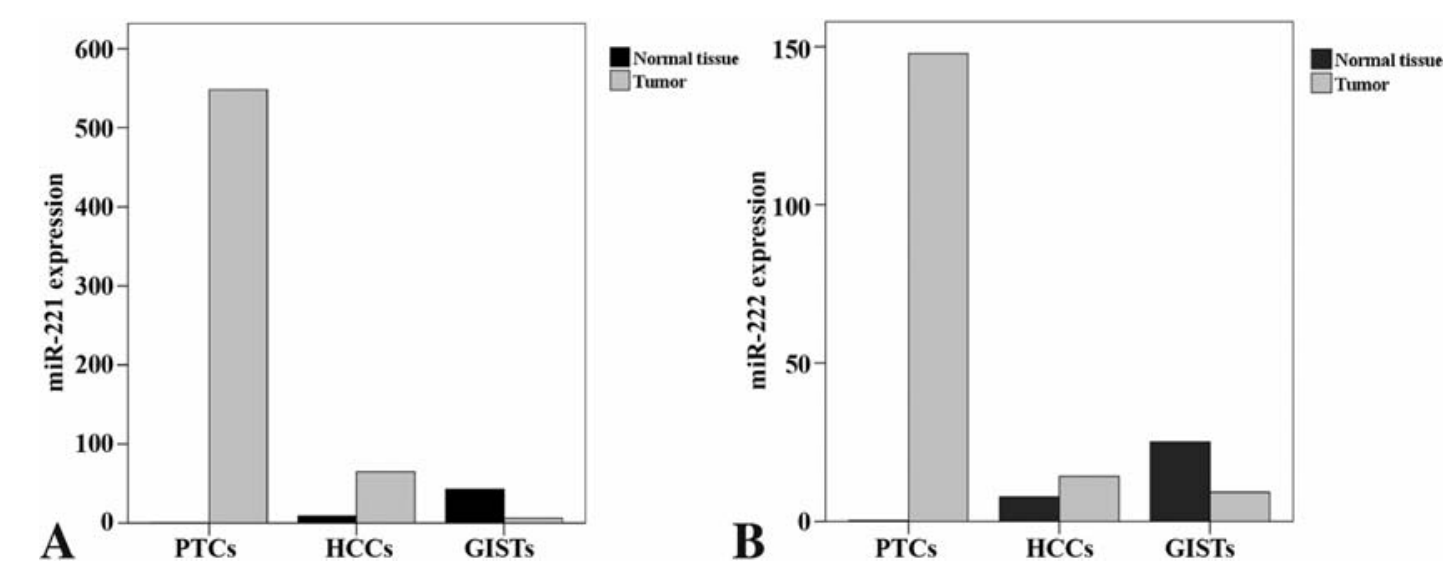

Figure 1. miR-expression in the set of preliminary analysed tumors, composed of three papillary thyroid carcinomas (PTCs), hepatocellular carcinomas (HCCs) and GISTs, respectively and corresponding peripheral non-tumorous tissue (normal tissue). (A) Median miR-221 expression levels. (B) Median miR-222 expression levels.

Statistical analyses were performed using SPSS software (Chicago, IL). Differences were analyzed with the MannWhitney or Kruskal-Wallis tests and the correlations were evaluated with Kendall and Spearman correlation coefficients, as the data were not normally distributed. A p-value of $<0.05$ was considered to be statistically significant.

\section{Results}

miR-221 and miR-222 are down-regulated in GISTs. miR221 and miR-222 have been suggested to be involved in the carcinogenesis of many tumor types. We analyzed the expression of miR-221 and miR-222 in a small set of tumors, composed of three papillary thyroid and hepatocellular carcinomas, and gastrointestinal stromal tumors, respectively, and compared the expression patterns with the corresponding peripheral non-tumorous tissue.

Both miRNAs were significantly increased in the hepatocellular and papillary thyroid carcinomas compared to the corresponding normal tissue. The three gastrointestinal stromal tumors revealed an inverse expression pattern, with a prominent down-regulation of these two miRNAs (Table III and Fig. 1).

Due to this surprising data, which showed a divergent expression of miR-221 and miR-222 in the gastrointestinal stromal tumors compared to the examined hepatocellular and papillary thyroid carcinomas, we decided to focus on the expression of miR-221 and miR-222 in a larger panel of well characterized GISTs. The composition of the GIST cohort is summarized in Table IV. The miR-221 and miR-222 expression levels were compared between the 54 tumors versus the corresponding non-tumorous tissue by real-time PCR analyses. A pronounced down-regulation in the tumorous tissue compared to the non-tumorous tissues was detected in most of the cases.

miR-221 and miR-222 levels are not associated to tumor risk, grade, mutation status or to the proliferation rate of GISTs. According to the method described by Fletcher et al (2), 15 tumors belonged to the high-risk group, 12 cases were 
Table IV. Summary of the features of the analyzed GISTs.

\begin{tabular}{|c|c|c|c|c|c|}
\hline Case & Location & Histological type & Risk grade & Mutation status & Kit expression \\
\hline 11 & Stomach & Spindle cell & High & KIT exon 11 mutation & +++ \\
\hline 23 & Stomach & Spindle cell & High & KIT exon 11 mutation & ++ \\
\hline 29 & Stomach & Spindle cell & High & KIT exon 11 mutation & +++ \\
\hline 48 & Stomach & Spindle cell & High & KIT exon 11 mutation & +++ \\
\hline 5 & Stomach & Spindle cell & Intermediate & KIT exon 11 mutation & ++ \\
\hline 17 & Stomach & Spindle cell & Intermediate & PDGFRA exon 18 mutation & - \\
\hline 19 & Stomach & Spindle cell & Intermediate & KIT exon 11 mutation & + \\
\hline 50 & Stomach & Spindle cell & Intermediate & No mutation & +++ \\
\hline 1 & Stomach & Spindle cell & Low & KIT exon 11 mutation & ++ \\
\hline 10 & Stomach & Spindle cell & Low & PDGFRA exon 18 mutation & + \\
\hline 14 & Stomach & Spindle cell & Low & KIT exon 11 mutation & - \\
\hline 18 & Stomach & Spindle cell & Low & PDGFRA exon 18 mutation & + \\
\hline 22 & Stomach & Spindle cell & Low & No mutation & +++ \\
\hline 26 & Stomach & Spindle cell & Low & PDGFRA exon 18 mutation & ++ \\
\hline 33 & Stomach & Spindle cell & Low & KIT exon 11 mutation & +++ \\
\hline 35 & Stomach & Spindle cell & Low & KIT exon 11 mutation & +++ \\
\hline 41 & Stomach & Spindle cell & Low & KIT exon 11 mutation & +++ \\
\hline 44 & Stomach & Spindle cell & Low & KIT exon 11 mutation & +++ \\
\hline 53 & Stomach & Spindle cell & Low & KIT exon 11 mutation & +++ \\
\hline 16 & Stomach & Spindle cell & Very low & KIT exon 11 mutation & +++ \\
\hline 27 & Stomach & Spindle cell & Very low & PDGFRA exon 12 mutation & +++ \\
\hline 28 & Stomach & Spindle cell & Very low & PDGFRA exon 18 mutation & + \\
\hline 8 & Stomach & Mixed & High & KIT exon 11 mutation & +++ \\
\hline 34 & Stomach & Mixed & High & KIT exon 11 mutation & +++ \\
\hline 49 & Stomach & Mixed & High & No mutation & +++ \\
\hline 30 & Stomach & Mixed & Intermediate & KIT exon 11 mutation & +++ \\
\hline 43 & Stomach & Mixed & Intermediate & PDGFRA exon 18 mutation & ++ \\
\hline 2 & Stomach & Mixed & Low & KIT exon 11 mutation & ++ \\
\hline 4 & Stomach & Mixed & Low & PDGFRA exon 18 mutation & + \\
\hline 21 & Stomach & Mixed & Low & PDGFRA exon 18 mutation & ++ \\
\hline 24 & Stomach & Mixed & Very low & No mutation & +++ \\
\hline 36 & Stomach & Epithelioid & High & PDGFRA exon 18 mutation & +++ \\
\hline 9 & Small intestine & Spindle cell & High & PDGFRA exon 18 mutation & + \\
\hline 20 & Small intestine & Spindle cell & High & KIT exon 11 mutation & + \\
\hline 42 & Small intestine & Spindle cell & High & KIT exon 11 mutation & +++ \\
\hline 6 & Small intestine & Spindle cell & Intermediate & KIT exon 11 mutation & +++ \\
\hline 25 & Small intestine & Spindle cell & Intermediate & No mutation & +++ \\
\hline 37 & Small intestine & Spindle cell & Intermediate & PDGFRA exon 18 mutation & +++ \\
\hline 47 & Small intestine & Spindle cell & Intermediate & No mutation & + \\
\hline 12 & Small intestine & Spindle cell & Low & KIT exon 11 mutation & ++ \\
\hline 15 & Small intestine & Spindle cell & Low & KIT exon 11 mutation & + \\
\hline 38 & Small intestine & Spindle cell & Low & KIT exon 9 mutation & +++ \\
\hline 46 & Small intestine & Spindle cell & Low & KIT exon 11 mutation & +++ \\
\hline 51 & Small intestine & Spindle cell & Low & KIT exon 11 mutation & +++ \\
\hline 7 & Small intestine & Spindle cell & Very low & No mutation & +++ \\
\hline 45 & Small intestine & Spindle cell & Very low & KIT exon 11 mutation & +++ \\
\hline 54 & Small intestine & Spindle cell & Very low & KIT exon 9 mutation & +++ \\
\hline 13 & Rectum & Spindle cell & High & No mutation & - \\
\hline 40 & Rectum & Spindle cell & Intermediate & KIT exon 11 mutation & +++ \\
\hline 52 & Rectum & Spindle cell & Low & KIT exon 11 mutation & +++ \\
\hline 31 & Mesentery & Spindle cell & High & No mutation & - \\
\hline 39 & Mesentery & Mixed & Intermediate & PDGFRA exon 18 mutation & + \\
\hline 32 & Mesentery & Epithelioid & High & PDGFRA exon 18 mutation & +++ \\
\hline 3 & Esophagus & Spindle cell & High & KIT exon 11 mutation & +++ \\
\hline
\end{tabular}

-, negative; +, weakly positive (score 1 and 2); ++, moderately positive (score 3 and 4); +++, strongly positive (score 5 and 6 ). 

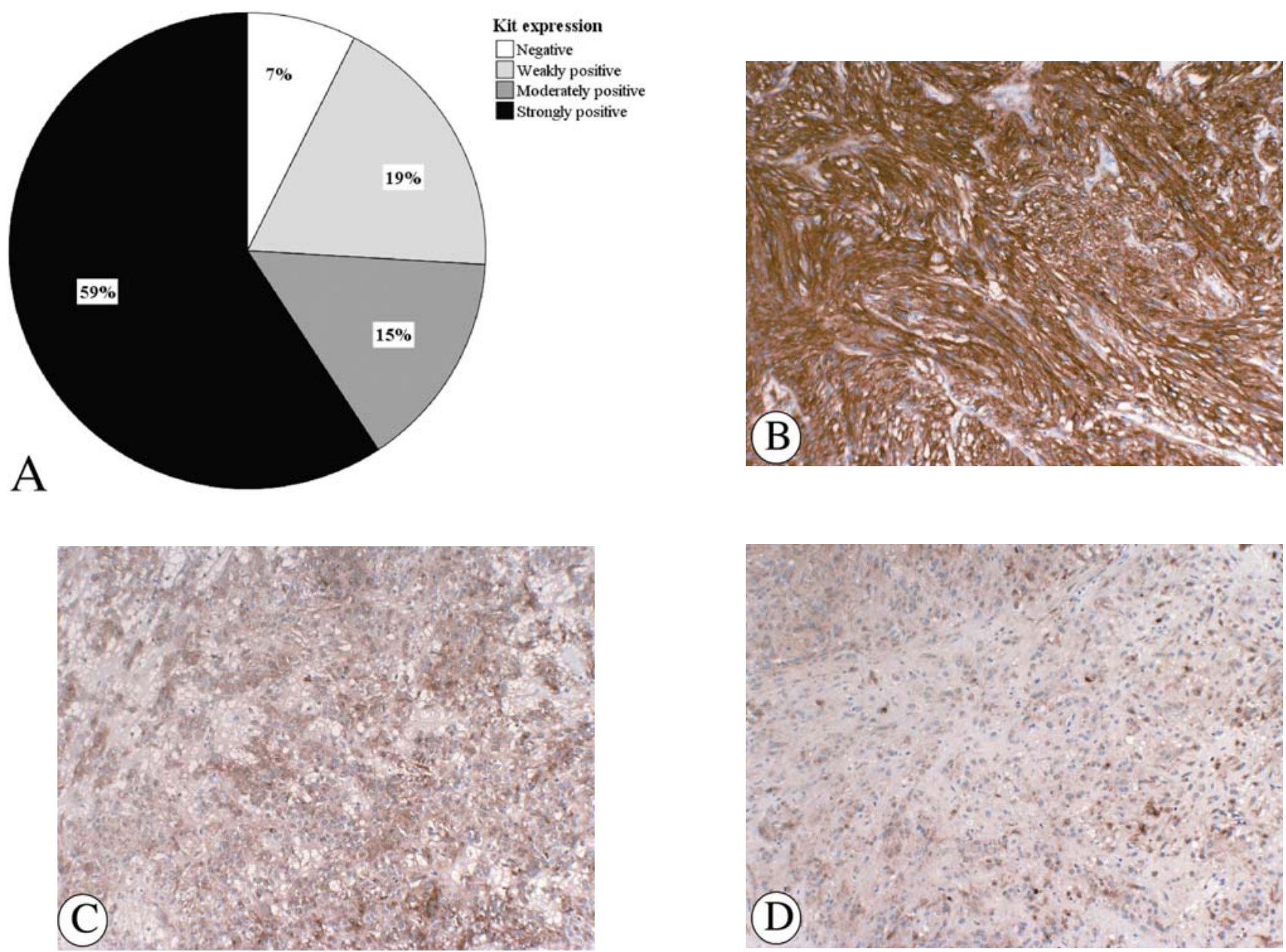

Figure 2. Kit expression in the analyzed GISTs. (A) Distribution of Kit (CD117) expression. (B) Case 46 exhibited a strong staining intensity for Kit. (C) A moderate staining intensity (case 43). (D) Example of a weak staining intensity in a mixed cell type with predominant spindle cells (case 39) (all original magnifications, $\mathrm{x} 200$ ).

classified as intermediate risk tumors, 20 tumors were of low-risk grade and seven tumors were of very low-risk grade. However, there was no correlation between miR-221 and miR-222 expression levels and tumor risk grade. Mutation analysis by genomic sequencing revealed c-KIT mutations in 31 cases $(57.4 \%)$, PDGFRA mutations in 14 cases $(25.9 \%)$ and 9 cases $(16.7 \%)$ with no mutations. In addition, the altered miR-221 and miR-222 expression was not linked to the mutation status of the tumors. The mean proliferation index of the GISTs was determined by Ki-67 staining and varied between 1 and $40 \%$. There was only a very low correlation between miR-222 expression and the proliferation rate (correlation coefficient, $0.306 ; \mathrm{p}=0.024$ ). However, there was no correlation between the proliferation rate and miR-221 expression (correlation coefficient, $0.248 ; \mathrm{p}=0.07$ ).

miR-221 and miR-222 are strongly repressed in Kit-positive GISTs. The Kit immunohistochemical staining analysis revealed a strong staining intensity in 32 tumors. A moderate staining intensity for Kit was observed in eight GISTs, ten tumors exhibited a weak intensity and four tumors showed negative staining for Kit (Fig. 2A-D).

The expression levels of miR-221 and miR-222 in the different groups of Kit expression intensity, especially between the Kit-negative and strongly positive tumors, revealed a significant difference (Fig. 3). The Kit-negative tumors revealed a higher expression level of miR-221 and miR-222 compared to the corresponding normal tissue, but there were only four Kit-negative cases in our GIST cohort. The expression levels of miR-221 and miR-222 in the group of Kit-positive tumors $(\mathrm{n}=50)$ however, exhibited a completely inverse expression pattern. The Kit-positive tumors revealed a significantly reduced miR-222 level, compared to the corresponding normal tissue $(\mathrm{p}=0.001)$. The miR-221 level was also distinctly reduced in the Kit-positive tumors in comparison to the corresponding normal tissue $(\mathrm{p}=0.005)$ (Fig. 4).

\section{Discussion}

We examined the expression of two already described miRNAs, miR-221 and miR-222, in a well characterized cohort of 54 GISTs and corresponding peripheral nontumorous tissue. GISTs have served as a prototype of tumors for molecular diagnostics as well as molecular targeted therapy. More than $95 \%$ of GISTs are characterized by the constitutive expression of Kit, a type III receptor tyrosine kinase, which is currently being studied as a potential 

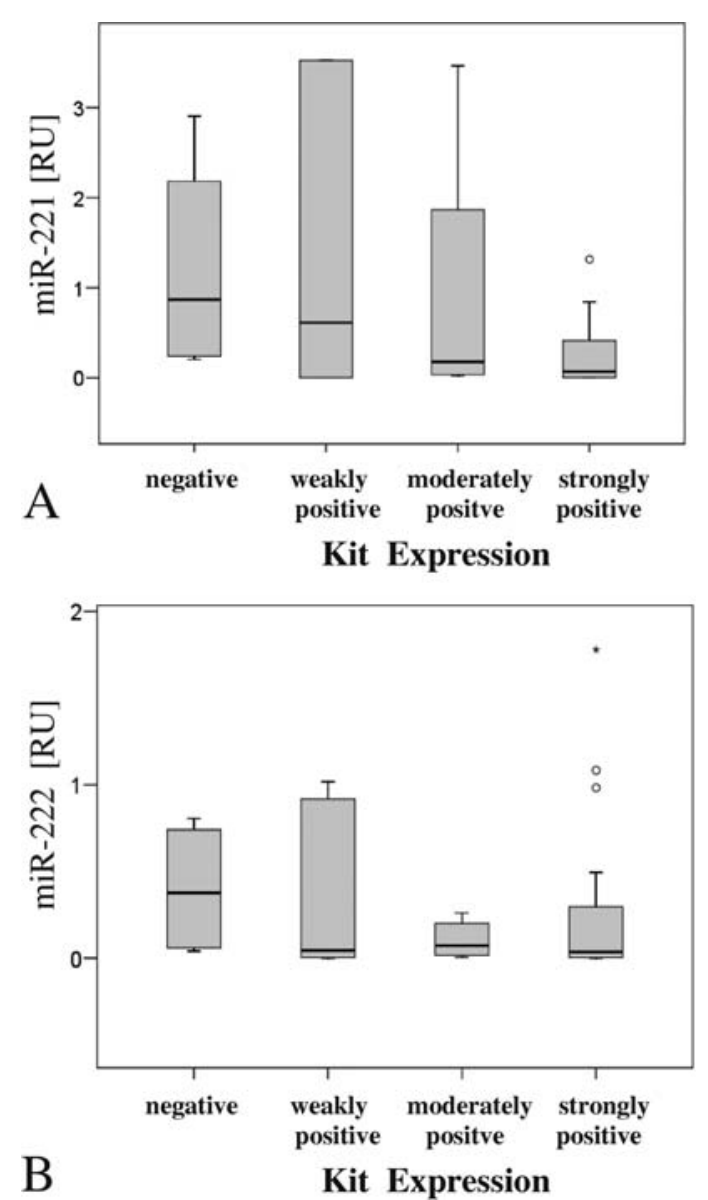

Figure 3. Median miR-221 and miR-222 levels in the different groups of immunohistochemical Kit expression (negative, score 0; weakly positive, score 1 and 2; moderately positive, score 3 and 4; strongly positive, score 5 and 6; see Materials and methods). (A) Median miR-221 levels, showing a considerable difference between Kit-negative (median expression level, 0.87 ) and strongly positive tumors (median expression level, 0.07). (B) Median miR-222 expression levels with again a major difference between Kit-negative (median expression level, 0.38) and strongly positive tumors (median expression level, 0.03).

therapeutic target $(1,2,9,10)$. miRNAs are a relatively new discovered class of small regulatory, non-coding RNAs with a prominent role in carcinogenesis (23-25). So far, no data concerning GISTs and miRNA expression exist.
In our current study, which included a small set of tumors, we found a surprisingly diminished expression of miR-221 and miR-222 in GISTs compared to the peripheral nontumorous tissue. In other studies, miR-221 and miR-222 have been found to be significantly up-regulated in analyzed tumors, such as papillary thyroid and hepatocellular carcinomas, pancreatic cancer, glioblastoma and prostate cancer $(37-40,43,47)$, and thus they have been designated as oncomiRNAs. However, the results from our study on miR-221 and 222 expression in GISTs, are contrary to those from previously analyzed tumors. Thus, miR-221 and miR-222 play a different role in GISTs. A possible explanation could be the fact that the expression of miRNAs per se can be influenced by various mechanisms, such as epigenetic changes or alterations in miRNA-transcription (25). Consequently, the miRNA expression in specific cells or tissues varies and accounts for an appropriate gene and protein expression pattern, in favour of the respective cell state. Hence, we consider the decreased expression of the miR-221/222 cluster as a new molecular feature of GISTs. An additional point is the multiple target domains of different miRNAs (25). A search in TargetScan ${ }^{\circledR}$ yielded 251 conserved target sites for the miR-221/222 cluster. So far, among them only the cell cycle regulatory protein $\mathrm{p} 27$ has been experimentally verified to be regulated by these two miRNAs in glioblastomas, papillary thyroid carcinomas and prostate cancer cell lines $(37,38,41,48)$. Also, p57 has been experimentally detected as another target of miR-221 in hepatocellular carcinoma (40). Considering the results from our study, namely that GISTs reveal a microR-221/222 expression pattern which is completely contrary to that found in previously analyzed tumors, it is doubtful whether these two miRNAs could also have the same target sites in GISTs as in other tumors.

Moreover, we observed a distinct expression pattern of miR-221 and miR-222 as regards immunohistochemical Kit expression, particularly between Kit-positive and -negative tumors, exhibiting a completely inverse expression pattern. Although we detected Kit expression only immunohistochemically, using a polyclonal antibody, the findings in our study strongly indicate an inverse regulatory influence of the miR-221/222 cluster on the expression of Kit. Based on this finding, we consider miR-221 and miR-222 to be modulators of Kit in GISTs. Felli et al have already experimentally
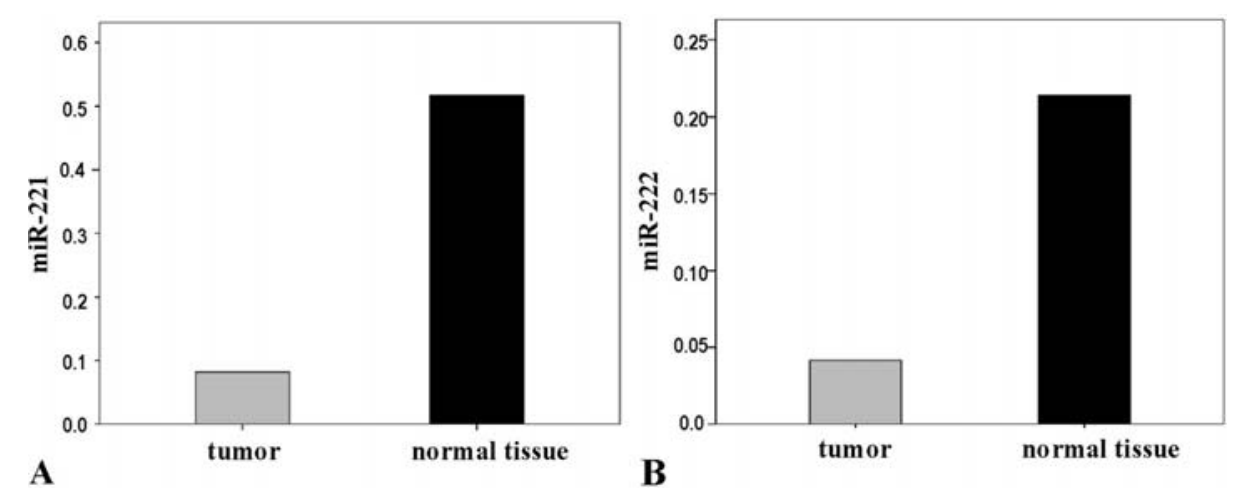

Figure 4. Median miR-221 and miR-222 expression in the group of Kit-positive tumors and corresponding peripheral, non-tumorous tissue from the resection margins of the surgical specimens $(\mathrm{n}=50$ ). (A) Median miR-221 expression in Kit-positive GISTs and corresponding normal tissue ( $\mathrm{p}=0.005$ ). (B) Median miR-222 expression in Kit-positive GISTs and corresponding normal tissue ( $\mathrm{p}=0.001)$. 
verified that miR-221 and miR-222 directly interact with the 3'-UTR of Kit in a luciferase targeting assay (35). The study by $\mathrm{He}$ et al (39) also describes an interaction of miRNAs 221, 222 and 146 with Kit in thyroid carcinomas, and in the progression of melanomas, Kit has also been shown to be regulated by miR-221 and miR-222 (36).

It should be noted, that Kit is the target of tyrosine kinase inhibitors, and is currently being applied in the therapy of GISTs. However, the current molecular targeted therapy is accompanied by secondary resistance, occurring in nearly half of the patients $(9,10,13,14)$. miRNAs, either addressed as new therapeutic targets or applied as therapeutic agents, show great promise in the future therapy of tumors $(49,50)$. Therefore, the observed modulation of Kit in GISTs by miR-221 and miR-222 and the fact that Kit holds a conserved miR-221 and miR-222 interaction site in its 3'-UTR (35), raises the aspect of a new therapeutic strategy in GISTs by silencing Kit with small synthesized RNA molecules.

In summary, we circumstantiate miR-221 and miR-222 as regulators of Kit expression in GISTs and hence as a new molecular aspect in the pathogenesis of these tumors. Although miR-221/222 expression does not have an impact on routine diagnostics, it could be a new therapeutic tool for the future therapy of GISTs, especially of tumors resistant to conventional tyrosine kinase inhibitor therapy.

\section{Acknowledgements}

This study was supported by the Nolting and Hochhaus Foundation/Faculty of Medicine, University of Cologne (grant to M.K.). We would like to thank Ali Manav and Katharina Wendland for their excellent technical support. We also thank Giuliano Ramadori (Department of Internal Medicine, Section of Gastroenterology and Endocrinology, Georg-August-University of Goettingen, Goettingen, Germany) for critical and constructive discussion.

\section{References}

1. Miettinen M and Lasota J: Gastrointestinal stromal tumors: review on morphology, molecular pathology, prognosis, and differential diagnosis. Arch Pathol Lab Med 130: 1466-1478, 2006.

2. Fletcher CD, Berman JJ, Corless C, et al: Diagnosis of gastrointestinal stromal tumors: A consensus approach. Hum Pathol 33: 459-465, 2002.

3. Badalamenti G, Rodolico V, Fulfaro F, et al: Gastrointestinal stromal tumors (GISTs): focus on histopathological diagnosis and biomolecular features. Ann Oncol 18 (Suppl 6): 136-140, 2007.

4. Rubin BP: Gastrointestinal stromal tumours: an update. Histopathology 48: 83-96, 2006.

5. Fletcher JA and Rubin BP: KIT mutations in GIST. Curr Opin Genet Dev 17: 3-7, 2007.

6. Lasota J, Jasinski M, Sarlomo-Rikala M and Miettinen M: Mutations in exon 11 of c-Kit occur preferentially in malignant versus benign gastrointestinal stromal tumors and do not occur in leiomyomas or leiomyosarcomas. Am J Pathol 154: 53-60, 1999.

7. Lasota J, Wozniak A, Sarlomo-Rikala M, et al: Mutations in exons 9 and 13 of KIT gene are rare events in gastrointestinal stroma tumors. A study of 200 cases. Am J Pathol 157: 1091-1095, 2000.

8. Corless CL, McGreevey L, Haley A, Town A and Heinrich MC: KIT mutations are common in incidental gastrointestinal stromal tumors one centimeter or less in size. Am J Pathol 160: 1567-1572, 2002.

9. Gold JS and Dematteo RP: Combined surgical and molecular therapy: the gastrointestinal stromal tumor model. Ann Surg 244: 176-184, 2006
10. Sleijfer S, Wiemer E and Verweij J: Drug Insight: gastrointestinal stromal tumors (GIST) - the solid tumor model for cancer-specific treatment. Nat Clin Pract Oncol 5: 102-111, 2008.

11. Debiec-Rychter M, Dumez H, Judson I, et al: Use of c-KIT/ PDGFRA mutational analysis to predict the clinical response to imatinib in patients with advanced gastrointestinal stromal tumours entered on phase I and II studies of the EORTC Soft Tissue and Bone Sarcoma Group. Eur J Cancer 40: 689-695, 2004.

12. Hornick JL and Fletcher CD: The role of KIT in the management of patients with gastrointestinal stromal tumors. Hum Pathol 38: 679-687, 2007.

13. Nishida T, Kanda T, Nishitani A, et al: Secondary mutations in the kinase domain of the KIT gene are predominant in imatinibresistant gastrointestinal stromal tumor. Cancer Sci 99: 799-804, 2008.

14. Antonescu CR, Besmer P, Guo T, et al: Acquired resistance to imatinib in gastrointestinal stromal tumor occurs through secondary gene mutation. Clin Cancer Res 11: 4182-4190, 2005.

15. Tabone S, Theou N, Wozniak A, et al: KIT overexpression and amplification in gastrointestinal stromal tumors (GISTs). Biochim Biophys Acta 1741: 165-172, 2005.

16. Michael MZ, SM OC, van Holst Pellekaan NG, Young GP and James RJ: Reduced accumulation of specific microRNAs in colorectal neoplasia. Mol Cancer Res 1: 882-891, 2003.

17. Iorio MV, Ferracin M, Liu CG, et al: MicroRNA gene expression deregulation in human breast cancer. Cancer Res 65: 7065-7070, 2005.

18. Kumar MS, Lu J, Mercer KL, Golub TR and Jacks T: Impaired microRNA processing enhances cellular transformation and tumorigenesis. Nat Genet 39: 673-677, 2007.

19. Bartel DP: MicroRNAs: genomics, biogenesis, mechanism, and function. Cell 116: 281-297, 2004.

20. Filipowicz W, Jaskiewicz L, Kolb FA and Pillai RS: Posttranscriptional gene silencing by siRNAs and miRNAs. Curr Opin Struct Biol 15: 331-341, 2005.

21. Carleton M, Cleary MA and Linsley PS: MicroRNAs and cell cycle regulation. Cell Cycle 6: 2127-2132, 2007.

22. Schickel R, Boyerinas B, Park SM and Peter ME: MicroRNAs: key players in the immune system, differentiation, tumorigenesis and cell death. Oncogene 27: 5959-5974, 2008.

23. Ma L and Weinberg RA: MicroRNAs in malignant progression. Cell Cycle 7: 570-572, 2008 .

24. Kent OA and Mendell JT: A small piece in the cancer puzzle: microRNAs as tumor suppressors and oncogenes. Oncogene 25: 6188-6196, 2006

25. Cowland JB, Hother C and Gronbaek K: MicroRNAs and cancer. APMIS 115: 1090-1106, 2007.

26. Calin GA and Croce CM: MicroRNA signatures in human cancers. Nat Rev Cancer 6: 857-866, 2006.

27. Wijnhoven BP, Michael MZ and Watson DI: MicroRNAs and cancer. Br J Surg 94: 23-30, 2007.

28. Cimmino A, Calin GA, Fabbri M, et al: $\mathrm{miR}-15$ and miR-16 induce apoptosis by targeting BCL2. Proc Natl Acad Sci USA 102: 13944-13949, 2005.

29. Johnson CD, Esquela-Kerscher A, Stefani G, et al: The let-7 microRNA represses cell proliferation pathways in human cells. Cancer Res 67: 7713-7722, 2007.

30. Akao Y, Nakagawa Y and Naoe T: MicroRNA-143 and -145 in colon cancer. DNA Cell Biol 26: 311-320, 2007.

31. Akao Y, Nakagawa Y and Naoe T: MicroRNAs 143 and 145 are possible common onco-microRNAs in human cancers. Oncol Rep 16: 845-850, 2006.

32. He L, Thomson JM, Hemann MT, et al: A microRNA polycistron as a potential human oncogene. Nature 435: 828-833, 2005.

33. Eis PS, Tam W, Sun L, et al: Accumulation of miR-155 and BIC RNA in human B cell lymphomas. Proc Natl Acad Sci USA 102: 3627-3632, 2005

34. Tam W and Dahlberg JE: miR-155/BIC as an oncogenic microRNA. Genes Chromosomes Cancer 45: 211-212, 2006.

35. Felli N, Fontana L, Pelosi E, et al: MicroRNAs 221 and 222 inhibit normal erythropoiesis and erythroleukemic cell growth via kit receptor down-modulation. Proc Natl Acad Sci USA 102: 18081-18086, 2005.

36. Felicetti F, Errico MC, Bottero L, et al: The promyelocytic leukemia zinc finger-microRNA-221/-222 pathway controls melanoma progression through multiple oncogenic mechanisms. Cancer Res 68: 2745-2754, 2008. 
37. Galardi S, Mercatelli N, Giorda E, et al: miR-221 and miR-222 expression affects the proliferation potential of human prostate carcinoma cell lines by targeting p27Kip1. J Biol Chem 282: 23716-23724, 2007.

38. Visone R, Russo L, Pallante P, et al: MicroRNAs (miR)-221 and miR-222, both overexpressed in human thyroid papillary carcinomas, regulate p27Kip1 protein levels and cell cycle. Endocr Relat Cancer 14: 791-798, 2007.

39. He H, Jazdzewski K, Li W, et al: The role of microRNA genes in papillary thyroid carcinoma. Proc Natl Acad Sci USA 102: 19075-19080, 2005.

40. Fornari F, Gramantieri L, Ferracin M, et al: MiR-221 controls CDKN1C/p57 and CDKN1B/p27 expression in human hepatocellular carcinoma. Oncogene 27: 5651-5661, 2008

41. Gillies JK and Lorimer IA: Regulation of p27Kip1 by miRNA 221/222 in glioblastoma. Cell Cycle 6: 2005-2009, 2007.

42. Pallante P, Visone R, Ferracin M, et al: MicroRNA deregulation in human thyroid papillary carcinomas. Endocr Relat Cancer 13: 497-508, 2006.

43. Lee EJ, Gusev Y, Jiang J, et al: Expression profiling identifies microRNA signature in pancreatic cancer. Int J Cancer 120: 1046-1054, 2007.

44. Schulte S, Oidtmann A, Kociok N, et al: Hepatocyte expression of angiotensin II type 1 receptor is downregulated in advanced human liver fibrosis. Liver Int 29: 384-391, 2008.
45. Wedemeyer I, Bechmann LP, Odenthal M, et al: Adiponectin inhibits steatotic CD95/Fas up-regulation by hepatocytes: Therapeutic implications for hepatitis C. J Hepatol 50: 140-149, 2009.

46. Varnholt H, Drebber U, Schulze F, et al: MicroRNA gene expression profile of hepatitis $\mathrm{C}$ virus-associated hepatocellular carcinoma. Hepatology 47: 1223-1232, 2008.

47. Ciafre SA, Galardi S, Mangiola A, et al: Extensive modulation of a set of microRNAs in primary glioblastoma. Biochem Biophys Res Commun 334: 1351-1358, 2005.

48. Le Sage C, Nagel R, Egan DA, et al: Regulation of the p27(Kip1) tumor suppressor by miR-221 and miR-222 promotes cancer cell proliferation. EMBO J 26: 3699-3708, 2007.

49. Tsuda N, Ishiyama S, Li Y, Ioannides CG, Abbruzzese JL and Chang DZ: Synthetic microRNA designed to target gliomaassociated antigen 1 transcription factor inhibits division and induces late apoptosis in pancreatic tumor cells. Clin Cancer Res 12: 6557-6564, 2006.

50. Krutzfeldt J, Rajewsky N, Braich R, et al: Silencing of microRNAs in vivo with 'antagomirs'. Nature 438: 685-689, 2005. 